\title{
Improving Student Nurses' Clinical-Reasoning Skills: Implementation of a Contextualised, Guided Learning Experience
}

\author{
Indriani Yauri ${ }^{1}$, Robyn Nash $^{2}$, Joanne Ramsbotham ${ }^{3}$ \\ ${ }^{1}$ Faculty of Nursing Universitas Katolik De La Salle, Manado, Indonesia \\ ${ }^{2}$ Faculty of Health Queensland University of Technology, Brisbane, Austalia \\ ${ }^{3}$ School of Nursing Queensland University of Technology, Brisbane, Australia \\ Corresponding email: iyauri@unikadelasalle.ac.id
}

Submitted: 20-03-2019 Accepted: 22-07-2019 Published: 01-08-2019

\begin{abstract}
Well-developed clinical reasoning skills are central to the process of clinical judgement. However, the results of recent studies suggest that curricula and teaching approaches that support student nurses' development of clinical reasoning skills have not yet been fully achieved. Cognitive apprenticeship offers a new approach to facilitate the development of complex thinking skills, for example, reasoning skills in making clinical decisions. This study examined the effect of an educational intervention utilizing principles of cognitive apprenticeship on students' ability to apply clinical reasoning skills within the context of a purpose-built clinical vignette. A quasiexperimental, non-equivalent control-group design was used to evaluate the effect of the educational intervention on students' accuracy, inaccuracy and self-confidence in clinical reasoning. Eighty-five undergraduate nursing students participated in the study. A purpose-built clinical vignette was utilised to collect data from study participants. Mixed-Design ANOVA with a significant level of $p<0.05$ was employed. Both quantitative and qualitative data were collected. A statistically significant increase in students' accuracy in clinical reasoning was found after the six-weeks educational intervention. Examination of the quantitative data at time 2 discovered a statistically significant higher accuracy in clinical reasoning score $(p<0.00)$ of the intervention group as compared to the control group. Results from inaccuracy and self-confidence in clinical reasoning did not reach significance. Results from the qualitative data are reported separately. It is argued that interplay of small group discussion of domain specific case-scenarios and the provision of guided learning experience may play a role in achieving partially successful results. This study makes an important contribution to nursing education by providing evidence to understand how best to facilitate nursing students' development of clinical reasoning.
\end{abstract}

Keywords: Clinical judgement, clinical reasoning, cognitive apprenticeship, educational intervention, nursing education. 
Indriani Yauri: Improving Student Nurses' Clinical-Reasoning Skills

\section{Introduction}

The development of clinical judgement and quality nursing graduates who can meet the demands of complex health settings remain an educational challenge. Developing nurses' clinical-reasoning skills is likely to contribute positively to the quality of clinical judgment in clinical practice (Alfaro-LeFevre, 2017, Johnsen, Slettebø, Fossum, 2016; Sar., Fitri, \& Widianti, 2017). Wosinski, Belcher, Dürrenberger, Allin, Stormacq \& Gerson, 2018). However, Tanner (2010) in an actionoriented plan for the future development of the nursing profession argue that nurses in the United States of America entering the field are not equipped with essential knowledge and clinical-reasoning skills for current practice, nor are they prepared to continue learning to meet the challenges of the nursing profession in the future. Similarly, Benner, Sutphen, Leonard, Day \& Shulman (2010) found that the nursing students in their study were poorly prepared to meet the current challenges of the healthcare sector, which led to their inability to cope with contemporary practice. Therefore, they argue that if clinical judgment is to be improved, nursing teachers need to focus on developing student nurses' clinical-reasoning skills by improving the pedagogical basis of educational interventions in this area.

Contemporary educational research highlights the importance of students' active engagement in learning, particularly in relation to the development of complex thinking skills, for example, reasoning skills in making clinical decisions. However, in a systemic review of the effectiveness and efficacy of educational interventions on clinical judgment, Thompson and Stapley (2011) found that results were unclear and the means to achieve positive effects are not yet known. For example, some current studies investigating the effect of Problem-Based Learning (PBL) showed that some issues are still prominent including students' familiarity and teachers' capability to conduct PBL (Wosinski et al., 2017; Gholami, Moghadam, Mohammadipoor, Tarahi, Sak, Toulabi, \& Pour, 2016; Mutiara, Suryani, Ikeu, 2017). This raises important questions about teaching approaches that might achieve better outcomes. Cognitive apprenticeship offers the opportunity to develop a novel educational approach to the development of clinicalreasoning skills within the undergraduate nursing context. Collins, Brown, and Newman (1989) defined cognitive apprenticeship as $\mathrm{a}$ 'learning-through-guided-experience' ( $\mathrm{p}$. 456) which focusses on the development of cognitive and metacognitive skills for solving complex problems. According to Collins, Brown, and Newman (1989), the focus on expert processes and situated learning within a collaborative environment enables students to build conceptual models of complex target skills and, thus, 'encourages both a deeper understanding of the meaning of the concepts themselves and a rich web of memorable associations between important concepts and problem-solving contexts' (p.3). Teaching students through cognitive apprenticeship enables making tacit processes visible to learners so that they can observe and practice them (Collins, Brown, \& Holum, 1991). These characteristics highlight the potential of cognitive apprenticeship as an innovative educational approach for facilitating the development and application of clinicalreasoning skills. Hence, this study aimed to examine the effect of an innovative teaching approach facilitating active engagement in clinical reasoning within the context of highrisk pregnancy on the learning experience of undergraduate nursing students at a university in North Sulawesi Province, Indonesia. This study makes an important contribution to nursing education by providing evidence to understand how best to facilitate nursing students' development of clinical reasoning.

Cognitive apprenticeship has been used in learning situations that involve interpretation and judgement in diverse fields such as nursing, medicine, science and teacher education (Maher, Gilmore, Feldon \& Davis, 2013; Wu, Hwang, Su \& Huang, 2012; Zurmehly, Lynd \& Leadingham, 2011) and has been growing in respect and popularity during the 2000 s due to its emphasis on social-constructivist methods of supporting development of cognitive skills and metacognitive skills.

Drawing on the work of Facione (2010) and Collins, Brown and Newman (1989), the educational intervention for this study was designed to provide explicit, well-designed 


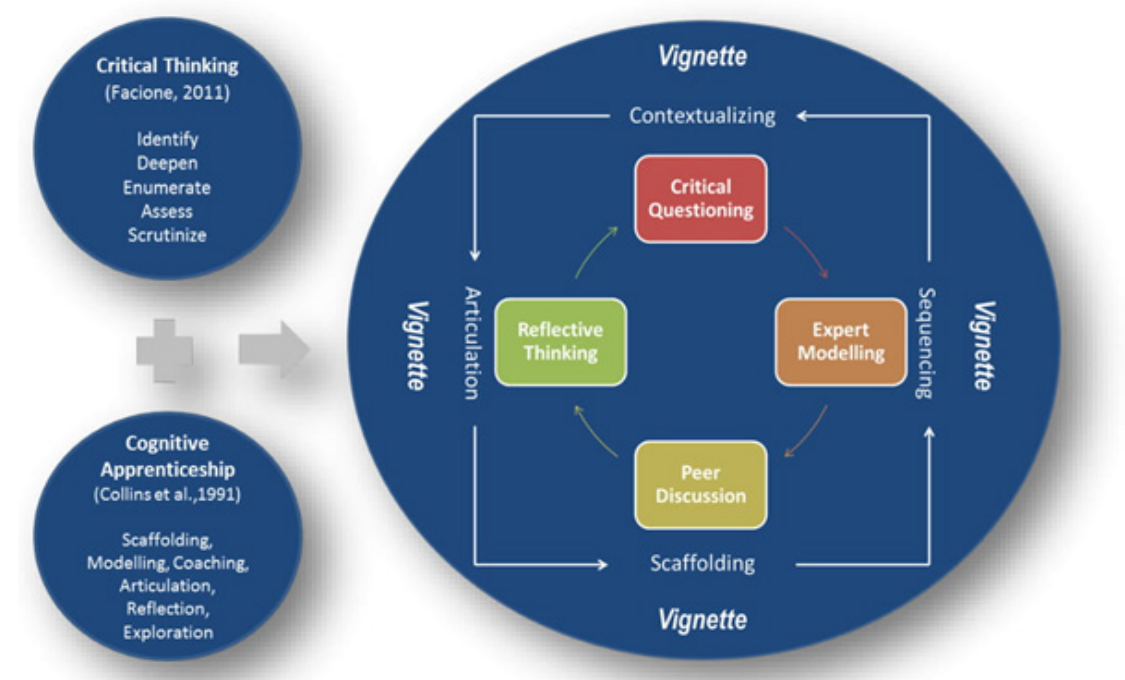

Figure 1 Clinical reasoning: a contextualised, guided learning experience Model (Yauri, 2015)

educational support to assist student nurses with the development of clinical-reasoning skills and their application in clinical-practice situations. The educational intervention package consists of two books: Teacher's guide and Students' workbook. As presented in Figure 1, the model for the educational intervention features four key teaching/ learning strategies (critical questioning, expert modelling, peer discussion and reflective thinking), which are complemented by four learning-enhancement strategies (contextualisation, sequencing, scaffolding and articulation). These strategies are described in the following section.

\section{Key teaching/learning strategies. \\ Critical questioning.}

The critical-questioning strategy can be described as a strategy designed to facilitate purposeful questions that target the development of clinical-reasoning skills (Merisier S., Larue C., Boyer L, 2018). Within the context of the vignette developed for this study, critical questions were developed to help students in the high-riskpregnancy nursing context undertake further patient-data collection; decide whether highrisk-pregnancy problem/s existed; prioritise identified problems; select the most relevant and feasible intervention/s based on a process of decision making; and reflect on the effectiveness of the decision made. Five critical questions included are 1) what are the facts?; 2) what are the key problems?; 3) what possible intervention can be done?; 4) what are the relevant and feasible interventions?; 5) how good was my thinking?

\section{Expert modelling.}

The expert-modelling strategy involved the demonstration of clinical-reasoning skills application by the expert (i.e. the teacher) to provide a 'real-life' model that would help students observe, conceptualise and develop a conceptual model of the processes important to accomplishing abstract skills that are largely 'hidden' from students' direct view (Herrington et al., 2010., Johnsen., Slettebø., Fossum, 2016). Expert modelling was employed in the educational intervention in this study using the 'think-aloud' approach, which is a process that involves the teacher verbalising their thinking. This approach includes the discussion of the assumptions, relevant evidence and the logic of the thinking process when solving problems.

\section{Peer discussion.}

The peer-discussion strategy focuses on the learner sharing ideas with other learners. Collins et al. (1989) believe that the presence of other learners provides learners with 'calibrations for their own progress, helping them to identify strengths and weaknesses and thus focus their efforts on improvement' (p. 486). Consequently, peer discussion was implemented as part of the key teaching/ 
Indriani Yauri: Improving Student Nurses' Clinical-Reasoning Skills

learning strategies in this study to allow students to share their thinking with the group and reflect on others' experiences (Chang, Chang, Kuo, Yang \& Chou, 2011; Wiggs, 2011). This study considered that learning through peer discussion would provide students with multiple roles and perspectives and assist the development of students' clinical-reasoning skills to solve clinical problems.

\section{Reflective thinking.}

As a form of metacognition, reflective thinking is the deliberate monitoring and correction of the one's cognitive strategies (Facione, 2011; Lai, 2011). When reflecting on experiences, students are able to identify both positive and negative experiences and construct a conceptual framework from their experiences. Studies have found that facilitating learning using reflective thinking enhances clinical reasoning (Kuiper et al., 2010; Facione, 2011). To stimulate students' reflective thinking, this study provided guiding reflective questions to the students after they completed each learning activity.

\section{Enhancement strategies.}

To operationalise the key teaching/ learning strategies, the learning strategies were complemented by four enhancement strategies that provided practical support for the delivery of the learning activities. The strategies are as follows.

\section{Contextualising.}

Contextualising learning instruction assists students to construct new meanings of concepts. Collins et al. (1991) argue that contextualising learning must represent the real world of practice. More importantly, must involve situations that would normally involve the knowledge being taught (Perin, 2011). In the educational intervention applied in this study, the contextualisation strategy framed learning activities based on the intended learning objectives within the context of high-risk-pregnancy nursing. Students were guided to build on their existing nursing knowledge and skills and develop new conceptual knowledge and clinical-reasoning skills relevant to highrisk-pregnancy care. Five clinical-reasoning questions were used to contextualised the learning activities.

\section{Sequencing.}

Sequencing learning instruction refers to a strategy used by the teacher to organise diversity and complexity of the learning content. In this study, students were assisted to work through three clinical vignettes that are structured with incremental levels of complexity: a simple clinical vignette, a more complex clinical vignette and a complex clinical vignette. This strategy aims to assist students to build a deeper and wider conceptual foundation of the learnt subject. By sequencing the learning activities, students obtain a general picture and comprehensive understanding of the tasks (Pritchard \& Woollard, 2010).

\section{Scaffolding.}

The scaffolding strategies in this study were informed by the concept of ZPD, which was originally designed to assist children to do something that could not be done without assistance (Herrington et al., 2010; Handwerker, 2012). The teacher should be able to identify the needs of the students and deliver relevant scaffolding strategies. In this study, scaffolding was performed in several ways. First, the teacher was located in the learning environment and actively listened to the peer discussion. Second, during the peer discussion, the teacher gave students hints to think about, for example, the teacher might prompt students to think about factors that were missing in the patient's clinical information or had not been fully considered by the student.

\section{Articulation.}

The articulation strategy involved facilitating students to express their ideas in the group. Being able to articulate reason in a logical and coherent manner indicates the use of the cognitive skills essential for reasoning (Facione, 2011). In the educational intervention implemented in this study, the students were prompted with questions that were designed to facilitate discussion about contradictions, inconsistencies, strong/weak points in students' thinking or to motivate the students to challenge each other's reasoning. 
Indriani Yauri: Improving Student Nurses' Clinical-Reasoning Skills

\section{Method}

The study was undertaken in two phases. Phase 1 was the development and content validation of an educational-intervention package. Phase 2 implemented the finalised educational intervention and evaluated with a cohort of Indonesian undergraduate nurses. A quasi-experimental, non-equivalent control-group design was used to examine the impact of the developed educational intervention on students' accuracy, inaccuracy and self-confidence in clinical reasoning. Implementation of the educational intervention occurred in the Faculty of Nursing at Catholic University of De La Salle Manado. Using survey questionnaire, Pretest data (Time 1) and post-test data (Time 2) were collected. Following the educational intervention, focus-group discussions were also conducted to explore the perceptions of intervention and control group participants regarding their learning experience. This paper focusses on the quantitative component of the Phase 2 data collection. The qualitative findings are reported separately.

\section{Sampling}

Following ethics approval from the University Human Research Ethics Committee (UHREC) (Reference No. 1200000588) of Queensland University of Technology, participants were drawn from a cohort of third-year student nurses in the Bachelor of Nursing undergraduate program (five-year degree). The total pool was 175 students. Convenience sampling strategy was employed. Eighty-five $(n=85)$ students consented to participate. These students were then randomly allocated into the intervention and control group. The same inclusion criteria for the intervention and control groups were employed; these were third-year nursing student enrolled in five-year programme at the Faculty of Nursing of CUDLSM, registered and studying Reproductive System II under the national nursing curriculum and having fulfilled the prerequisite course Reproductive System I.

\section{Instruments}

A purpose built instrument (the clinical vignette) was constructed to allow the evaluation of clinical-reasoning skills. The clinical vignette was a short, purposedesigned scenario that described a health situation related to high-risk pregnancy. Drawing upon previous work by Botti and Reeve (2003), it contained relevant, but insufficient information about an existing health problem. It also contained information that was irrelevant to the problem. If students wished, they were allowed to request additional information about the problem as they worked through the vignette. The content of the vignette was based on the undergraduate nursing curriculum and the maternity nursing texts (Ackley, 2011; Chapman, 2010) that were relevant to the high risk pregnancy subject being studied by the study participants. Using a system adapted from Botti and Reeve (2003), students' responses were scored. In addition, participants were asked to identify their level of self-confidence in the process of thinking on a $1-5$ scale where $1=$ Not confident at all and $5=$ Extremely confident. This scale was adapted from the Student Satisfaction and Self-Confidence in Learning published by the National League for Nursing (NLN) (National League for Nursing, 2012) since the original version was developed for assessing students' self-confidence in a simulation context. Two processes were employed to assess the content validity of the clinical vignette including review by an expert panel and review by a sample of undergraduate nursing students. Results of the validation processes are reported separately.

\section{Implementation}

The usual teaching by the control group was lectures and group presentation. The lectures mainly involved teacher-centred learning and focused on relevant content and learning outcomes. For the group presentations, students formed groups of approximately $7-8$ students and each group was allocated a specific topic to prepare and present to the class. In addition, student preparation for the presentations was outside the lecture time and no teacher guidance was provided during the preparation. In contrast to the usual teaching approach, the educational intervention focused on students working in small groups (5-6 students per 
Indriani Yauri: Improving Student Nurses' Clinical-Reasoning Skills

group) on case-based scenarios that became progressively more complex throughout the implementation period. Consistent with the principles of Cognitive Apprenticeship, a key feature of the group work environment was the provision of expert modelling, coaching and explicit guidance by the teacher where needed. Thinking aloud and reflection on thinking by students and the teacher occurred throughout the group interactions. Implementation of the study occurred over a period of six weeks within the high-riskpregnancy nursing care subject that was part of the National Bachelor of Nursing curriculum. During this period, the group work activities occurred on a weekly basis for three hours per session. Teaching activities in the intervention group were performed by the researcher while the usual teaching was implemented by the subject teachers.

\section{Data Collection}

Data were collected at pre-test (Time 1) and post-test (Time 2). Students were asked to respond to the five clinical reasoning questions which accompanied the clinical vignette, and had the opportunity to request additional information as they worked through the clinical vignette. Two outcomes were measured using the clinical vignette: 1) students' clinical reasoning; and 2) students' perceived self-confidence in clinical reasoning. Students' clinical reasoning was measured using two primary variables - accuracy and inaccuracy in clinical reasoning. The clinical vignette that was developed for evaluating the educational intervention was a short, purpose-designed scenario describing a health situation related to high-risk pregnancy. It contained relevant but insufficient information about a 'problem' being experienced by a woman receiving antenatal care. The clinical vignette also contained information that was irrelevant to the 'problem' (Ackley \& Ladwig, 2011; Chapman \& Durham, 2010). Students were asked to respond to the five clinical reasoning questions provided, which accompanied the clinical vignette, and had the opportunity to request additional information as they worked through the clinical vignette (Yauri, 2015). In addition, they were asked to rate their level of self-confidence in responding to every question, using five levels of selfconfidence ranging from 1 (not confident at all) to 5 (extremely confident).

\section{Data Analysis}

Group means and standard deviations were calculated. Sphericity test showed equality of variance of the differences between each pair of the measured values. Therefore, Group and Time differences were analysed by MixedDesign Anova. A significance level of alpha $(p<0.05)$ was used and eta squared $\left(\eta^{2}\right)$ was calculated.

\section{Results}

Eighty per cent of the participants in this study were aged 19-21 years, and

Table 1 Changes at Time1 and Time 2 in Overall Scores for Intervention and Control Groups

\begin{tabular}{|c|c|c|c|c|c|c|}
\hline \multirow[t]{2}{*}{ Variables } & \multirow[t]{2}{*}{ Time } & \multicolumn{2}{|c|}{$\begin{array}{l}\text { Control Group } \\
\quad(n=43)\end{array}$} & \multicolumn{2}{|c|}{$\begin{array}{l}\text { Intervention Group } \\
\qquad(\mathrm{n}=\mathbf{4 2})\end{array}$} & \multirow[t]{2}{*}{ M Difference } \\
\hline & & $\mathbf{M}$ & SD & $\mathbf{M}$ & SD & \\
\hline \multirow{2}{*}{$\begin{array}{l}\text { Accuracy } \\
\text { in clinical } \\
\text { reasoning }\end{array}$} & 1 & 6.86 & 1.35 & 6.67 & 1.30 & 0.19 \\
\hline & 2 & 6.12 & 1.24 & 9.74 & 1.4 & 3.62 \\
\hline \multirow{2}{*}{$\begin{array}{l}\text { Inaccuracy } \\
\text { in clinical } \\
\text { reasoning }\end{array}$} & 1 & 8.65 & 1.65 & 8.74 & 1.86 & 0.09 \\
\hline & 2 & 8.44 & 1.39 & 7.48 & 1.58 & 0.96 \\
\hline \multirow{2}{*}{$\begin{array}{l}\text { Self- } \\
\text { confidence } \\
\text { in clinical } \\
\text { reasoning }\end{array}$} & 1 & 86.63 & 20.56 & 70.60 & 14.81 & 16.03 \\
\hline & 2 & 72.84 & 11.28 & 72.83 & 14.03 & 0.01 \\
\hline
\end{tabular}


Indriani Yauri: Improving Student Nurses' Clinical-Reasoning Skills

Table 2 Changes at Time1 and Time 2 in Overall Scores for Intervention and Control Groups: MD ANOVA Results

\begin{tabular}{lcccc}
\hline \multicolumn{1}{c}{ Variables } & Effect $\mathbf{( F )}$ & $\mathbf{F}$ & Sig. & $\mathbf{\eta}^{\mathbf{2}}$ \\
\hline Accuracy in clinical & Group & 49.68 & 0.000 & 0.37 \\
reasoning & Time & 57.90 & 0.000 & 0.41 \\
& Group X Time & 155.6 & 0.000 & 0.65 \\
Inaccuracy in & Group & 2.84 & 0.095 & 0.03 \\
clinical reasoning & Time & 9.96 & 0.002 & 0.11 \\
& Group X Time & 5.09 & 0.027 & 0.03 \\
Self- confidence in & Group & 1.29 & 0.26 & 0.01 \\
clinical reasoning & Time & 0.002 & 0.96 & 0.01 \\
& Group X Time & 2.35 & 0.13 & 0.00 \\
*p $<0.05$ & & & &
\end{tabular}

approximately 85 per cent were women. Data from participants' demographic characteristics showed sample homogeneity. The Phase 2 results indicated that educational intervention had a positive impact on the accuracy of participants' clinical reasoning. This was indicated by their responses to a purpose-built clinical vignette and comments in regard to their learning experiences within each of the study conditions. Participants' preand post-test scores for accuracy, inaccuracy and self-confidence in clinical reasoning are reported in Tables 1 and 2 .

As shown in the Table1, there was an increase in the mean of overall accuracy scores for intervention group students from time 1 (6.67) to time 2 (9.74). In fact, the mean of overall accuracy scores of the intervention group was higher than the control group as many as 3.62. Although there was a decrease in overall accuracy scores for intervention group students from time 1 (8.74) to time 2 (7.48), the overall scores on inaccuracy in clinical reasoning, the mean difference between the control and intervention groups at time 2 was very small $(<1)$. Furthermore, the control group had a higher overall score for self-confidence in clinical reasoning than the intervention group at Time 1 but had no difference in the mean overall score at Time 2. To avoid Type 2 errors, changes both from Time 1 and Time 2 as well as differences between the overall scores for intervention and control groups were analysed using a Mixed-Design ANOVA. Details of results are shown in Table 2.

A Mixed-Design ANOVA analysis revealed a significant interaction effect between Group and Time, Wilks' Lambda = $0.35, \mathrm{~F}(1,83)=155.6, \mathrm{p}=0.000$, with a very large effect size $\left(\eta^{2}=0.65\right)$. Similarly, there was a significant main effect for Time, Wilks' Lambda $=0.59, \mathrm{~F}(1,83)=57.90, \mathrm{p}=0.000$, $\eta^{2}=0.41$ (very large effect size) with an increase in the mean overall accuracy scores for intervention group students. A significant main effect was also found for Group, F (1, $83)=49.68, p=0.000$, with partial eta square showing a very large effect size $\left(\eta^{2}=0.37\right)$ (Pallant, 2013), suggesting a difference in the effectiveness of the educational intervention and usual teaching on students' overall accuracy in clinical reasoning. This results depicted a statistically significant increase in students' accuracy in clinical reasoning after the six-weeks educational intervention. As multiple comparisons in MD ANOVA employ the Bonferroni correction to prevent Type I error, a more stringer alpha level is used. With inaccuracy in clinical reasoning, there were no significant differences $(p>0.05)$ found between the two groups at Time 1 or Time 2 for the overall scores. Similarly, results from self-confidence in clinical reasoning did not reach significance.

\section{Discussion}

The present study found significant differences in the accuracy of students' clinical reasoning for those who received the educational intervention compared to those who received usual teaching. However, the 
results for inaccuracy in clinical reasoning were insignificant between the two teaching approaches. Students participating in the study were in the third year of a fiveyear Bachelor of Nursing programme and were not experienced in domain-specific knowledge. Perhaps, similar to Botti and Reeve's (2003) study, the lack of significance seen in the inaccuracy results of the present study might be related to the students' lack of experience with the subject content and the fact that higher level ability is required to make precise discriminations between what may be unfamiliar data - as opposed to the recognition of more familiar data - and hence, the differential effects on accuracy and inaccuracy seen in the intervention group's clinical reasoning.

Results from the intervention and control groups' responses to self-confidence in clinical reasoning revealed no significant differences between the intervention and control groups' perceived self-confidence at either Time 1 or Time 2. However, there were trends in the data that suggested that at Time 2, the intervention-group students perceived a high level of self-confidence in identifying possible interventions, selecting the most appropriate interventions, and in their decision-making process compared to the control-group students. This result differs to findings from a longitudinal study by Patterson (2006). The results suggested that students' self-confidence was significantly increased. The differences between Patterson's study and the present study suggest that the shorter length of the current study might have influenced the results. This highlights the possible influence of time and practice in developing student self-confidence in clinical-reasoning skills.

It is possible that the lack of statistical significance in the results for students' selfconfidence reflected an overconfidence factor that has been reported by Berner and Graber (2008). According to these authors, people are more likely to rate their confidence beyond the accuracy of those judgements and notably, overconfidence seems to disappear in easy tasks but intensify with difficult tasks. The intervention and control groups in the present study might have responded overconfidently to the clinical-reasoning questions at Time 1 by choosing 'confident' or 'extremely confident'. Consequently, the levels of self-confidence after the educational intervention were perceived to be similar to the self-confidence levels expressed at Time 1. As a result, a significant difference between Time 1 and Time 2 was not detected. Despite insignificant results, the intervention group demonstrated a positive direction in changes in self-confidence, while the control group revealed a negative trend in self-confidence in clinical reasoning.

Reflecting on the overall findings of this study, it is proposed that three key factors were instrumental in achieving the partially positive outcomes including situating the knowledge through case-based learning; making clinical reasoning visible using a 'think-aloud' approach with students; enhancing collaboration through small peer-group discussion. Situating knowledge through case-based learning was a key element of the design and implementation of the educational intervention. According to Brown et al. (1989), situating learning in an authentic context (i.e. situations that would usually involve the relevant knowledge and skills) assists students to develop the cognitive and metacognitive skills important to solving real-life problems. Contextualising learning according to culture and the environment where the knowledge is constructed and employed enables students to develop conceptual models of the targeted tasks or procedures before practicing the knowledge and skills in the real environment (Brown et al., 1989). Thus, contextualising learning facilitates the development of expertise in a specific area (Brown et al., 1987; Collins et al., 1991), which includes disciplinary knowledge (e.g. key concepts, principles and demonstration of procedures), techniques or approaches for making judgements, and self-regulation (e.g. ability to identify, select appropriate strategies and re-evaluate decisions made if needed).

For the purpose of the present study, the learning activities were contextualised within case scenarios that were drawn from examples of high-risk-pregnancy situations that students are likely to encounter in their everyday practice. This differs from the usual teaching methods used within the Bachelor 


\section{Indriani Yauri: Improving Student Nurses' Clinical-Reasoning Skills}

of Nursing at CUDLSM, which generally involve more traditional didactic approaches. Studies support the use of case-based learning to develop students' cognitive and metacognitive skills (Wosinski et. al., 2018; Gholami et al., 2016). During the process of problem solving, students need to recursively monitor and correct their decisions in previous steps or use their metacognitive skills (Wosisnski et al., 2018; Gholami et al., 2016). Thus, compared to didactic instruction, the use of a case-scenario approach offers a potentially more effective manner in which to assist students to connect what they are learning to the knowledge and skills required in real-life situations.

As discussed by Brown et al. (1987), a key element of cognitive apprenticeship is to make the process of thinking used by experts visible to students to enable their development of the cognitive and metacognitive skills needed to solve complex problems. In a cognitiveapprenticeship approach, expert thinking is made transparent through community-ofpractice interactions between students and teachers. To learn expert thinking, students are required to participate actively in the activities and observe how experts use their thinking to solve the complex problems in real-life situations.

To facilitate the visualisation of expert thinking, the present study employed a 'thinkaloud' approach in which teacher verbalised their thinking. This included discussion of the assumptions, clinical-reasoning logic and usage of relevant evidence in relation to the case scenarios (Calleja et al., 2011; Pinnock $\&$ Welch, 2014). This is different from the usual teaching method employed in the Bachelor of Nursing course at CUDLSM, in which the expert thinking is generally hidden, as teachers do not verbalise their process of thinking. The focus in this course is on traditional learning through the informationdissemination approach that requires students to memorise content (Collins et al., 1991; Dennen \& Burner, 2008).

The think-aloud approach can be beneficial for both teachers and students. Using of this approach, students can observe the thinking processes employed by the teacher to solve complex problems and, consequently, they can observe how knowledge and skills are employed (Johnsen., Slettebø., \& Fossum, 2016). When the think-aloud approach is used interactively with students participating in the exchange, they are able to make linkages between the current information being provided and knowledge from their long-term memory (Gazzaniaga et al., 2010). Facilitating the articulation of their thinking processes enables students to self-assess their thinking and subsequently self-correct their thinking and, thus, their metacognitive skills development. For teachers, thinking aloud interactively with students can also act as an assessment strategy. It allows teachers access to students' cognitive and metacognitive processes and thus provides formative information on the level of support needed by the students. For these reasons, scholars argue that the think-aloud approach is an effective strategy for enhancing students' clinical reasoning (Forsberg, Ziegert, Hult \& Fors, 2013; Johnsen., Slettebø., \& Fossum, 2016)

Collaboration through a small-group discussion was another key element of the design and implementation of the educational intervention employed in the present study. Learning through collaboration is consistent with the community-of-practice concept, which emphasises the social dimension of learning and knowing. In a community of practice, the sharing of perspective, expertise, experiences, activities, information and knowledge promote the active participation of the community members (Collins et al., 1991; Laal \& Ghodsi, 2012), which allows the creation of collaborative learning environments that engage students and teachers (Collins et al., 1991). Learners become involved in a community of practice, which can transform passive ways of learning to active participation in the learning experience. As discussed by Karagiorgi and Symeou (2005), collaborative learning environments enable students to develop, compare and understand multiple perspectives of an issue, as well as develop a meaningful understanding through developing and evaluating the opinions of others. This is consistent with Collins et al.'s (1991) views on the sociology aspect of the learning environment, which emphasises the importance of the social process in providing 


\section{Indriani Yauri: Improving Student Nurses’ Clinical-Reasoning Skills}

opportunities for students to observe procedures and attitudes demonstrated by the expert, as well as the values, judgement processes and cultural elements that inform the thinking process and decisions made. Laal \& Ghodsi (2012). believe that students can experience pleasure and satisfaction when they solve a problem. According to Gazzaniaga et al. (2010), positive learning experiences are more likely to be repeated. Arguably, experiencing pleasure and selfsatisfaction in learning is an effective precursor to enhance self-confidence and continual use of problem solving as the students' manner of learning. It is important that communication between teachers and students facilitate students to share their thinking in a non-threatening environment (Laal \& Ghodsi, 2012).

In the present study, collaboration was facilitated in the small peer-group discussions of case scenarios in the context of highrisk pregnancy. The group discussions were designed to provide opportunities for students to develop, compare and understand multiple perspectives through meaningful activity and social interaction. Learning was guided by the teacher using relevant strategies such as thinking aloud and providing hints. This differs from the usual teaching methods used in the Bachelor of Nursing course at CUDLSM, which generally involve teachercentred learning and are focused on individual activities and learning achievement. Studies support the use of a collaborative learning approach to develop students' clinicalreasoning skills.

Considering all the results of this study, it is argued that the interplay between authentic contextualisation of learning, the use of a 'think-aloud' approach to model expert clinical reasoning, and the promotion of peer collaboration through small peergroup discussions conducted in an informal environment facilitated more effective learning outcomes for students in the intervention group (compared to the students in the control group). The contextualisation of learning provided by the educational intervention gave this group a clear and relevant learning context and activities that fostered a meaningful learning experience for students. This was scaffolded by the deliberate use of the think-aloud approach by the teacher and supported by the small-group discussion, which promoted students' active participation in the learning activities.

\section{Conclusion}

This study found that the educational intervention implemented in this study demonstrated some positive effects on students' development of clinical-reasoning skills. These findings highlight the benefit of a contextualised learning experience, collaborative construction of knowledge and the role of thinking aloud in achieving positive outcomes for students' clinicalreasoning skills; these are the key of the positive outcomes of this study. In particular, the educational intervention was identified as able to enhance accuracy in clinical reasoning in the intervention-group students and provide a more enjoyable learning experience for the students. Having a clear educational model will enable teachers to reflect critically on the construction of learning experiences that facilitate students' development of habits of inquiry and complex thinking skills. From the overall results of the study, it is argued that the educational intervention had a number of positive effects in relation to facilitating students' clinical-reasoning skills. Further research to investigate the effectiveness of the educational intervention with a larger sample size will be needed.

\section{References}

Ackley, B. J. \& Ladwig, G. B. (2011). Nursing diagnosis handbook: An evidencebased guide to planning care. St Louis, MO: Mosby.

Alfaro-LeFevre, R. (2017). Critical thinking, clinical reasoning, and clinical judgment (6th Ed.). Philadelphia:Elsevier, Inc.

Benner, P., Sutphen, M., Leonard, V., Day, L. \& Shulman, L. S. (2010). Educating nurses: A call for radical transformation. Retrieved from http://QUT.eblib.com.au/patron/ FullRecord.aspx? $p=468681$. 
Indriani Yauri: Improving Student Nurses' Clinical-Reasoning Skills

Berner, E. S., \& Graber, M. L. (2008). Overconfidence as a cause of diagnostic error in medicine. The American Journal of Medicine, 121(5), S2-S23.

Benner, P., Sutphen, M., Leonard, V., Day, L. \& Shulman, L. S. (2010). Educating nurses: $A$ call for radical transformation. Retrieved from http://QUT.eblib.com.au/patron/ FullRecord.aspx? $\mathrm{p}=468681$.

Botti, M., \& Reeve, R. (2003). Role of knowledge and ability in student nurses' clinical decision making. Nursing \& Health Sciences, 5(1), 39-49.

Brown, J. S., Collins, A. \& Duguid, P. (1989). Situated cognition and the culture of learning. Educational Researcher, 18(1), 32-42.

Calleja, P., Nash, R. E., Tippett, V., Harvey, T., Wirihana, L. A., \& Malouf, N. (2011). Using 'think aloud'as a strategy for learning clinical reasoning in high fidelity case-based simulation for undergraduate nursing students. Queensland University of Technology. Brisbane, Australia.

Chang, M. J., Chang, Y. J., Kuo, S. H., Yang, Y. H. \& Chou, F. H. (2011). Relationships between critical thinking ability and nursing competence in clinical nurses. Journal of Clinical Nursing, 20(21-22), 3224-3232.

Chapman, L. \& Durham, R. F. (2010). Maternal-newborn nursing: The critical components of nursing care. Philadelphia, PA: F.A. Davis Company.

Collins, A., Brown, J. S. \& Holum, A. (1991). Cognitive apprenticeship: Making thinking visible. American Educator, 15(3), 6-11.

Dennen, V. P., \& Burner, K. J. (2008). The cognitive apprenticeship model in educational practice. In J. M. Spector, M. D. Merrill, J. Van Merrienboer, \& M. P. Driscoll (Eds.), Handbook of educational communications and technology (pp. 425-439). Mahwah, NJ: Erlbaum.

Facione, P. (2011). THINK critically. Upper Saddle River, NJ: Prentice Hall.
Forsberg, E., Ziegert, K., Hult, H. \& Fors, U. (2013). Clinical reasoning in nursing, a think-aloud study using virtual patients-A base for an innovative assessment. Nurse Education Today, 34(4), 538-542.

Gazzaniaga, M. S., Heatherton, T. F. \& Halpern, D. F. (2010). Psychological science (3rd ed.). New York, NY: W.W. Norton \& Company, Inc.

Gholami, Moghadam, Mohammadipoor, Tarahi., Sak, Toulabi, \& Pour. (2016). Comparing the effects of problem-based learning and the traditional lecture method on critical thinking skills and metacognitive awareness in nursing students in a critical care nursing course. Nurse Education Today, 45:16-21. Retrieved from https://doi. org.10.1016/j.nedt.2016.06.007.

Handwerker, SM (2012). Transforming nursing education: a review of current curricular practices in relation to Benner's latest work. International Journal of Nursing Education Scholarship,9(1) Retrieved from https://doi.org/10.1515/1548-923X.2510.

Herrington, J., Reeves, T. \& Oliver, R. (2010). A guide to authentic e-learning. New York, NY: Routledge.

Johnsen, H. M., Slettebø, A., \& Fossum, M. (2016). Registered nurses' clinical reasoning in home healthcare clinical practice: A thinkaloud study with protocol analysis. Nurse education today, 40, 95-100.

Karagiorgi, Y. \& Symeou, L. (2005). Translating constructivism into instructional design: Potential and limitations. Journal of Educational Technology \& Society, 8(1), 1727.

Kuiper, R., Murdock, N. \& Grant, N. (2010). Thinking strategies of baccalaureate nursing students prompted by self-regulated learning strategies. Journal of Nursing Education, 49(8), 429-436. doi: 10.3928/0148483420100430-01.

Laal, M. \& Ghodsi, S. M. (2012). Benefits of collaborative learning. Procedia-Social and 
Indriani Yauri: Improving Student Nurses' Clinical-Reasoning Skills

Behavioral Sciences, 31(0), 486-490. doi: 10.1016/j.sbspro.2011.12.091.

Lai, E. R. (2011). Critical thinking: $A$ literature review. Pearson Research Report.

Maher, M. A., Gilmore, J. A., Feldon, D. F. \& Davis, T. E. (2013). Cognitive apprenticeship and the supervision of science and engineering research assistants. Journal of Research Practice, 9(2), Article M5. Retrieved from http://jrp.icaap.org/index.php/jrp/article/ view/354/311.

Merisier, S., Larue, C., \& Boyer, L. (2018). How does questioning influence nursing students' clinical reasoning in problem-based learning? A scoping review. Nurse education today, 65, 108-115.

Mutiara, M., Suryani, S., Ikeu, N. (2017). Perspektif mahasiswa mengenai ProblemBased learning (PBL). (Student Perspectives Regarding Problem-Based Learning (PBL)). Journal Keperawatan Padjadjaran, 1(3), 290-301.

National League for Nursing (NLN). (2012). Educational Practices Questionnaire: Students Satisfaction and Self-Confidence in Learning, NLN Laerdal Research Tools. New York, NY: National League for Nursing. Retrieved from http://sirc.nln.org/mod/page/ view.php?id $=88$.

Pallant, J. F. (2013). SPSS survival manual: A step by step guide to data analysis using IBM SPSS. Crows Nest: Allen \& Unwin.

Perin, D. (2011). Facilitating student learning through contextualization: A review of evidence. Community College Review, 39(3), 268-295. doi: 10.1080/07370000802584539 Pinnock, R. \& Welch, P. (2014). Learning clinical reasoning. Journal of Paediatrics and Child Health, 50(4), 253-257. doi: 10.1111/ jpc. 12455.

Patterson, J. S. (2006). Increased student self-confidence in clinical reasoning skills associated with case-based learning (CBL). Journal of Veterinary Medical Education, 33(3), 426-431.

Volume 7 Issue 2 August 2019
Pritchard, A. \& Woollard, J. (2010). Psychology for the classroom: Constructivism and social learning. Retrieved from http:// QUT.eblib.com.au/patron/FullRecord. aspx? $\mathrm{p}=515360$.

Sari, C. W. M., Fitri, S. Y. R., \& Widianti, E. (2017). Critical Thingking and Decision Making Skills Based Learning Methods at The Faculty of Nursing Universitas Padjadjaran. Jurnal Pendidikan Keperawatan Indonesia, 3(2), 126-130.

Tanner, C. A. (2010). Transforming pre licensure nursing education: Preparing the new nurse to meet emerging health care needs. Nursing Education Perspectives, 31(6), 347-353.

Thompson, C. \& Stapley, S. (2011). Do educational interventions improve nurses' clinical decision making and judgement? A systematic review. International Journal of Nursing Studies, 48(7), 881-893. doi: 10.1016/j.ijnurstu.2010.12.005.

Wiggs, C. M. (2011). Collaborative testing: Assessing teamwork and critical thinking behaviours in baccalaureate nursing students. Nurse Education Today, 31(3), 279-282.

Wosinski, J., Belcher, A. E., Dürrenberger, Y., Allin, A. C., Stormacq, C., \& Gerson, L. (2018). Facilitating problem-based learning among undergraduate nursing students: A qualitative systematic review. Nurse education today, 60, 67-74.

Wu, P.-H., Hwang, G.-J., Su, L.-H. \& Huang, Y.-M. (2012). A context-aware mobile learning system for supporting cognitive apprenticeships in nursing skills.

Yauri, I. (2015). Exploring an Innovative Educational Approach to Facilitating Student Nurses' Clinical-Reasoning Skills in North Sulawesi Province, Indonesia (Doctoral dissertation). Queensland University of Technology, Brisbane.

Zurmehly, J., Lynd, M., \& Leadingham, C. (2011). Skilful coaching: New directions in teaching health assessment. Journal of College Teaching \& Learning, 1(4), 57-62. 